\title{
A rare case report of Blepharophimosis syndrome associated with esotropia and nystagmus
}

\author{
Kalaria H. ${ }^{1}$, Sabnis M. ${ }^{2}$, Kulkarni V. ${ }^{3}$, Devkar P. ${ }^{4}$ \\ DOI: https://doi.org/10.17511/jooo.2020.i06.08 \\ 1* Hardik Kalaria, MBBS, 3rd Year Resident, Department of Ophthalmology, Dr. D. Y. Patil Medical College Hospital and Research Institute, \\ Kolhapur, Maharashtra, India. \\ 2 Milind Sabnis, Professor and Head, Department of Ophthalmology, Dr. D. Y. Patil Medical College Hospital and Research Institute, \\ Kolhapur, Maharashtra, India. \\ ${ }^{3}$ Vedesh Kulkarni, MBBS, 3rd Year Resident, Department of Ophthalmology, Dr. D. Y. Patil Medical College Hospital and Research Institute, \\ Kolhapur, Maharashtra, India. \\ 4 Parag Devkar, MBBS, 2nd Year Resident, Department of Ophthalmology, Dr. D. Y. Patil Medical College Hospital and Research Institute, \\ Kolhapur, Maharashtra, India.
}

The authors report here a rare case of blepharophimosis syndrome which was associated with esotropia and nystagmus. Blepharophimosis syndrome is a clinical entity characterized by blepharophimosis, ptosis, epicanthus inversus, and telecanthus. In our case, it was also associated with horizontal nystagmus and esotropia. Our patient also had a bilateral mature cataract. It can either be type 1 or type 2 depending on the associated systemic manifestations. The present study describes a case of BPES type 2 with associated nystagmus and esotropia with a bilateral mature cataract.

Keywords: BPES syndrome, Blepharophimosis, Ptosis, Epicanthus inversus, Telecanthus, Nystagmus and esotropia

Corresponding Author

Hardik Kalaria, MBBS, 3rd Year Resident, Department of Ophthalmology, Dr. D. Y. Patil Medical College Hospital and Research Institute, Kolhapur, Maharashtra, India.

Email: hardikkalaria999@gmail.com
How to Cite this Article

Kalaria H, Sabnis M, Kulkarni V, Devkar P. A rare case report of Blepharophimosis syndrome associated with esotropia and nystagmus. Trop J Ophthalmol Otolaryngol. 2020;5(6):163-167. Available From https://opthalmology.medresearch.in/index.php/jooo /article/view/156

\section{To Browse}

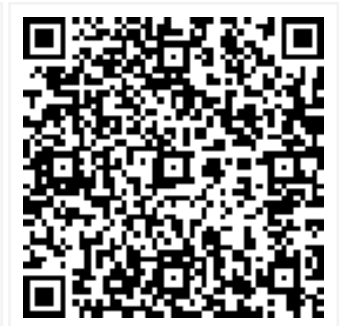

\section{Introduction}

BPES or blepharophimosis, ptosis, epicanthus inversus syndrome is a quartet of clinical anomalies of eyelids specifically characterized by blepharophimosis, ptosis, epicanthus inversus, and telecanthus. The inheritance is autosomal dominant [1] in nature.
Embryological evidence suggests that upper and lower eyelids fuse together by the $8^{\text {th }}$ week of development and separate again by $5^{\text {th }}$ and $7^{\text {th }}$ month [2]. Humans have been found to have abnormal eyelid development, however the molecular events associated with this eyelid development have not yet been fully understood $[3,4]$.

\begin{tabular}{|c|c|}
\hline $\begin{array}{c}\text { Manuscript Received } \\
2020-07-31\end{array}$ & $\begin{array}{c}\text { Review Round } 1 \\
2020-08-16\end{array}$ \\
\hline $\begin{array}{c}\text { Conflict of Interest } \\
\text { No }\end{array}$ & $\begin{array}{c}\text { Funding } \\
\mathrm{Nil}\end{array}$ \\
\hline
\end{tabular}

$$
\begin{aligned}
& \text { Review Round } 2 \\
& 2020-08-23 \\
& \text { Ethical Approval } \\
& \text { Yes }
\end{aligned}
$$


Some progress has now been made to understand the molecular genetics associated with this syndrome [5]. It is predominantly divided into two types: BPES type 1 and BPES type 2; type 1 refers to the classical syndrome complex associated along with premature ovarian failure, whereas type 2 refers to the syndrome complex exclusively limited to the ocular manifestations. Various ocular manifestations may include lacrimal duct anomalies, strabismus, amblyopia, and refractive errors. Other extraocular manifestations may include broad nasal bridge, low set ears, and short philtrum [6]. Diagnosis of BPES is made on clinical presentation, however various genetic aberrations of the gene FOXL2 have been also implicated.

Genetics: Blepharophimosis, ptosis, epicanthus inversus syndrome is an autosomal dominant disorder; the causative gene of which is FOXL2, which is localized to the $3 q 23$ chromosome. The genetic aberrations associated are mainly translocations or interstitial deletions of the $3 q 23$ chromosome. The development of the ovary and the eyelid is affected by the FOXL2 gene [7].n

\section{Case Report}

The present study hereby reports a 65 -year-old male who reported to the outpatient department of DY Patil hospital Kolhapur with complaints of decreased vision for the last 6 months. The patient gave no history of systemic disease, ocular trauma, or ocular surgeries in the past and allergy to any medications. The patient had drooping of eyelids since birth and there was a family history of similar eyelid complaints in his father, sister, brother, brother's daughter, and son (Figure 1).

Pedigree chart

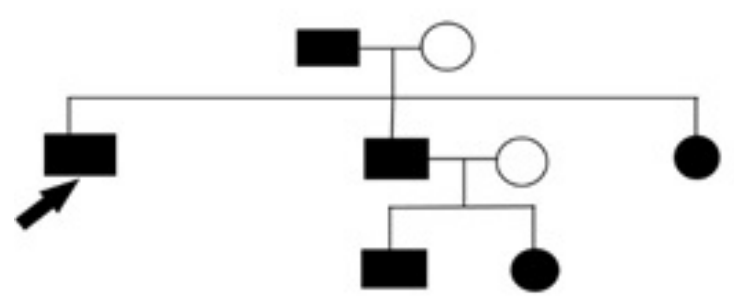

Fig-1: Pedigree chart (The arrow indicates patient).

On ocular examination, the resting gaze of the patient had a backward head tilt with arching of eyebrows [Figure 2]. On examination of the lower lids, it was seen that a vertical fold of skin arose
From the lower lid that was inserted in the upper lid medially suggestive of epicanthus inversus [Figure 3]. The patient also had increased distance between the medial canthi of around $35 \mathrm{~mm}$ which is suggestive of telecanthus [Figure 4]. The patient presented with horizontal nystagmus. The patient also had esotropia of $45^{\circ}$ in the left eye. The patient had severe bilateral ptosis with a flat nasal bridge and there was overaction of the frontalis muscle [Figure 5]. The length of the vertical palpebral fissures is around $3 \mathrm{~mm}$ and that of horizontal palpebral fissures was $21 \mathrm{~mm}$ which is suggestive of blepharophimosis [Figures 6 and 7]. There was an increase in the size of eyelashes (trichomegaly). There was deficient action of the LPS and absent upper eyelid crease. The corneal examination revealed bilateral opacities in lower $1 / 3$ rd of the cornea suggestive of healed exposure keratitis. Conjunctival examination in both eyes was normal. Bilateral lenticular examination showed opacities of pearly white color indicating bilateral mature cataract.

The BCVA of the patient was the perception of light and projection of rays in all four quadrants. Lacrimal sac syringing shows patency of both the nasolacrimal duct. The fundus examination shows hazy media due to cataracts. B-scan of both eyes shows no abnormalities in the posterior segment.

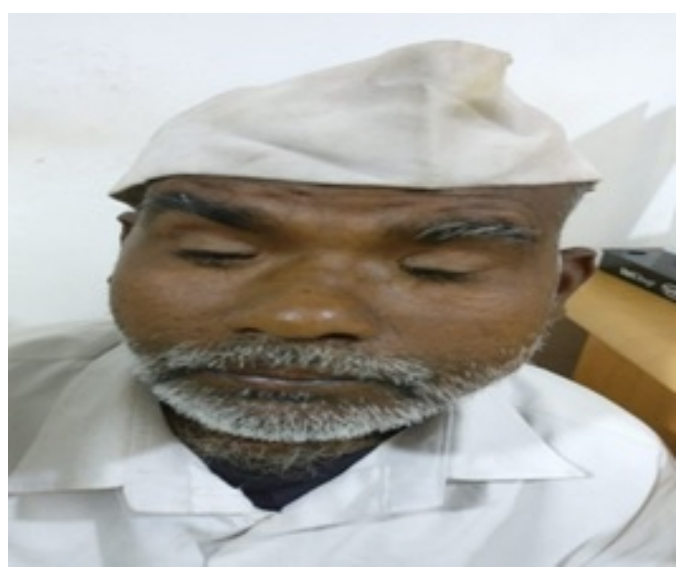

Fig-2: Initial ocular examination of the patient.

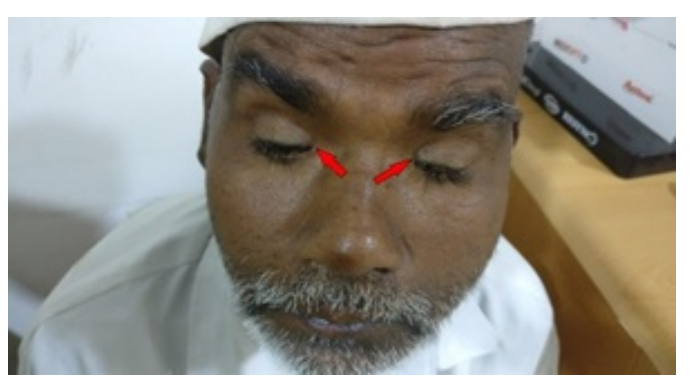

Fig-3: Arrows indicate epicanthal inversus. 


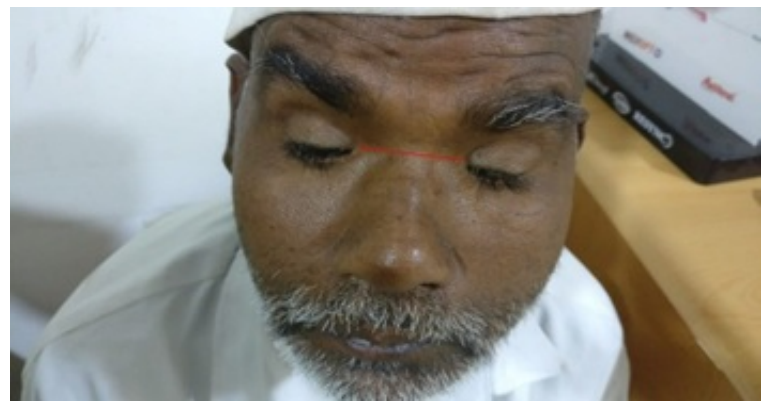

Fig-4: The red line indicates telecanthus.

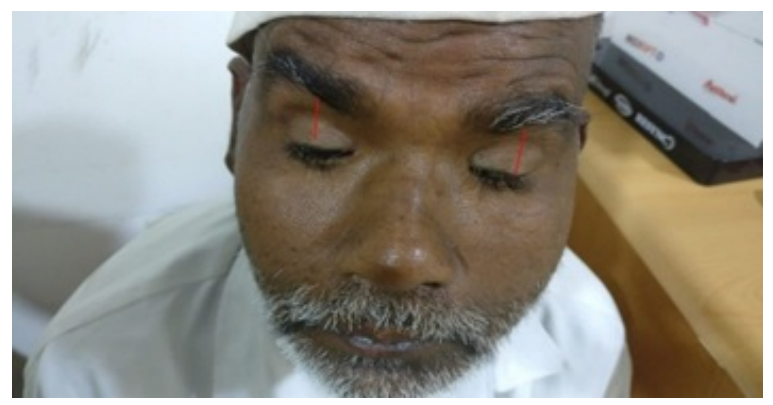

Fig-5: The red lines indicate ptosis.

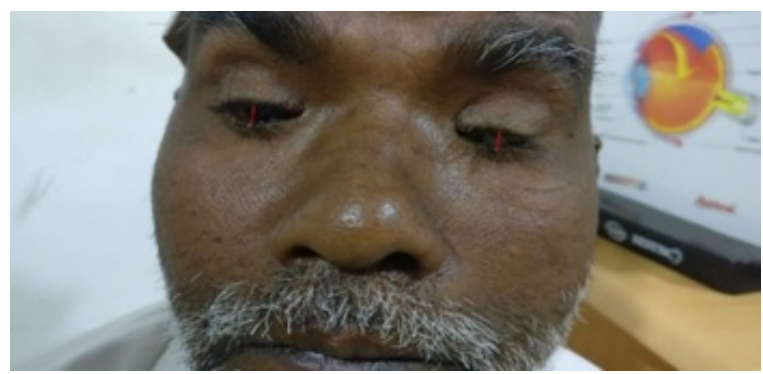

Fig-6: Red lines indicate a vertical palpebral fissure size of around $3 \mathrm{~mm}$.

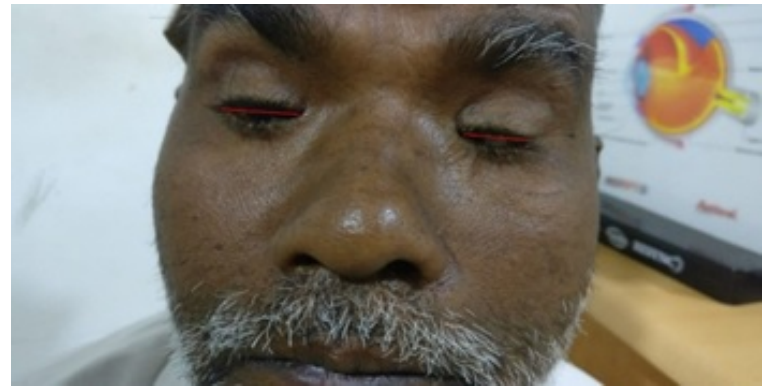

Fig-7: The red lines indicate the horizontal palpebral fissure of around $21 \mathrm{~mm}$.

\section{Discussion}

Blepharophimosis was first described by Von Ammon in 1841 and Vignes first described BEPS in 1889 after which it has been repeatedly described in literature throughout the globe [8]. Treatment of
BPES syndrome consists of eyelid surgery [9]. In this report, six members of the same family were affected across three generations. In a separate Chinese study, in a family, there were 12 affected individuals across 3 generations [10].

The surgical management of BPES is usually carried out in two stages, the first of which is to perform a medial canthoplasty for the correction of blepharophimosis, epicanthus inversus, and telecanthus and it is usually done between three to five years. The second stage is the correction of ptosis, done about a year later with a brow suspension procedure. The surgical procedure chosen for medial canthoplasty depends on the size of epicanthal folds. In the case of small epicanthal folds, $Y-V$ canthoplasty is performed and if the epicanthal folds are severe, then double Z-plasty is performed [11].

Ptosis correction in adults is done mostly by frontalis muscle flap suspension. In order to have a good cosmetic outcome and improved muscle function, Decock et al preferred the method of super-maximal resection and frontalis suspension [12].

An alternate procedure in which, medial canthoplasty and ptosis correction is performed simultaneously has also been described [13]. Study shows that one-stage correction with standard surgical techniques is not just safe, but also efficient by two retrospectives, interventional studies performed on 21 subjects [14,15].

The causes of abnormal lower eyelid position have now been researched to greater depths and hence has made possible more targeted surgical reconstruction that allows more natural appearance [16].

Another procedure that has been described for blepharophimosis is lateral canthoplasty described by Aginew [17], in which lateral canthotomy and cantholysis is done after which mobilization of the conjunctiva is done and then attached to the skin at the lateral canthus. The lateral fornix is formed by a double arm suture.

Mustarde's rectangular flap operation is also considered to give better results than the $\mathrm{V}-\mathrm{Y}$ procedure as described by Verwey $[18,19]$. In this procedure, paramarginal incisions are made first after which the lids are stretched. This prevents any damage to the canaliculi and also prevents the development of postoperative ectropion. The medial 
Palpebral ligament is shortened and fixed medially to the periosteum with the help of merselene thread.

In our case, as the vision recovery of the patient was important, a bilateral mature cataract first right eye was operated followed by the left eye after 15 days. Following which lid reconstruction was planned in steps. In the first step, it was planned to do medial canthoplasty and in the second step ptosis correction with silicon, the sling was planned. However, the patient has lost follow up.

\section{Reference}

01. Cai T, Tagle DA, Xia X, Yu P, He XX, Li LY, et al. A novel case of unilateral blepharophimosis syndrome and mental retardation associated with de novo trisomy for chromosome 3q. J Med Genet. 1997;34(9)772-776.

doi: $10.1136 / j m g .34 .9 .772$ [Crossref]

02. Sevel D. A reappraisal of the development of the eyelids. Eye. 1988;2(Pt 2)123-129.

doi: 10.1038/eye.1988.25 [Crossref]

03. Oley C, Baraister M. Blepharophimosis, ptosis, epicanthus inversus syndrome (BPES syndrome). J Med Genet. 1988;25(1)47-51.

doi: $10.1136 /$ jmg.25.1.47 [Crossref]

04. Vassalli A, Matzuk MM, Gadnr HAR, Lee KF, Jaenisch R. Activin/inhibin[beta] $\beta$ subunit gene disruption leads to defects in eyelid development and female reproduction. Genes Dev. $1994 ; 8(4) 414-427$.

doi: $10.1101 /$ gad.8.4.414 [Crossref]

05. Maw M, Kar B, Biswas J, Biswas $P$, Nancarrow D, Bridges $R$, Kumaramanickavel $G$, Denton $M$, Badrinath SS. Linkage of blepharophimosis syndrome in a large Indian pedigree to chromosome 7p. Human Mol Genet. 1996;5(12)2049-2054.

doi: $10.1093 / \mathrm{hmg} / 5.12 .2049$ [Crossref]

06. Verdin H, De Baere E. Blepharophimosis, Ptosis, and Epicanthus Inversus, In- Adam MP, Ardinger $\mathrm{HH}$, Pagon RA, et al, editors, GeneReviews ${ }^{\circledR}$ [Internet]. Seattle (WA)- University of Washington, Seattle. 1993-2020.

[Crossref]
07. Allen C, Rubin P. Blepharophimosisptosisepicanthus inversus syndrome (BPES)- clinical manifestation and treatment. Int Ophthalmol Clin. 2008;48(2)15-23.

doi: 10.1097/IIO.0b013e3181694eee [Crossref]

08. Oley C, Baraitser M. Blepharophimosis, ptosis, epicanthus inversus syndrome (BPES syndrome). J Med Genet. 1988;25(1)47-51.

doi: $10.1136 / j m g .25 .1 .47$ [Crossref]

09. Beckingsale PS, Sullivan TJ, Wong VA, Oley C. Blepharophimosis- a recommendation for early surgery in patients with severe ptosis. Clin Experiment Ophthalmol. 2003;31(2)138-142. doi: $10.1046 /$ j.1442-9071.2003.00621.x [Crossref]

10. Tang SJ, Wang XK, Wang YL, Lin LX, Sun Y. The mutation study of the FOXL2 gene in a big Chinese family with blepharophimosis-ptosisepicanthus inversus syndrome. Zhonghua Zheng Xing Wai Ke Za Zhi. 2007;23;48-50.

[Crossref]

11. Sa HS, Lee JH, Woo KI, Kim YD. A new method of medial epicanthoplasty for patients with blepharophimosis-ptosis-epicanthus inversus syndrome. Ophthalmol. 2012;119(11)24022407.

doi: 10.1016/j.ophtha.2012.05.037 [Crossref]

12. Decock CE, Shah AD, Delaey C, Forsyth $R$, Bauters W, Kestelyn $P$, et al. Increased levator muscle function by supramaximal resection in patients with blepharophimosis-ptosisepicanthus inversus syndrome. Arch Ophthalmol. 2011b;129(8)1018-1022.

doi: 10.1001/archophthalmol.2011.218 [Crossref]

13. Wu SY, Ma L, Tsai YJ, Kuo JZ. One-stage correction for blepharophimosis syndrome. Eye. $2008 ; 22(3) 380-388$.

doi: $10.1038 /$ sj.eye.6702644 [Crossref]

14. Liu H, Shao $Y$, Zhao Z, Zhang D. One-stage correction of blepharophimosis-ptosisepicanthus inversus syndrome using a frontalis muscle transfer technique. J Plast Surg Hand Surg. 2014;48(1)74-79.

doi: $10.3109 / 2000656 \times .2013 .819004$ [Crossref] 
15. Sebastiá R, Herzog Neto G, Fallico E, Lessa S, Solari HP, Ventura MP. A one-stage correction of the blepharophimosis syndrome using a standard combination of surgical techniques. Aesthetic Plast Surg. 2011;35(5)820-827.

doi: $\quad 10.1007 / \mathrm{s} 00266-011-9702-3 \quad$ [Crossref]

16. Hughes LW. Surgical Treatment of Congenital Palpebral Phimosis. AMA Arch Ophthalmol. 1955;54(4)586-590.

doi: $\quad$ 10.1001/archopht.1955.00930020592012 [Crossref]

17. Aginew H. Ocular surgery New York. McGraw Hill Book Co. 1952.

[Crossref]
18. Aleksandra I, Andrzej Z, Edward L, Bogusław A, Tomasz Z. Evaluation of the Surgical Treatment for Congenital Blepharoptosis Using Mustarde's Modified Method. Pol Przegl Chir. 2016;88(3)155-159.

[Crossref]

19. Decock CE, Claerhout I, Leroy BP, Kesteleyn $P$, Shah AD, De Baere E. Correction of the lower eyelid malpositioning in the blepharophimosisptosis-epicanthus inversus syndrome. Ophthal Plast Reconstr Surg. 2011a;27(5):368-370. doi: $10.1097 /$ IOP.0b013e31821b6c58 [Crossref] 